\title{
Hereditary Fructose Intolerance
}

National Cancer Institute

\section{Source}

National Cancer Institute. Hereditary Fructose Intolerance. NCI Thesaurus. Code C84720.

A genetic disorder characterized by the absence of the enzyme aldolase- $B$ from the liver. This enzyme is essential for the metabolism of fructose. Signs and symptoms from fructose ingestion are evident in infancy and include vomiting, abdominal pain and hypoglycemia. Long term complications include hepatic and renal failure. 